\title{
A Computational Model of Dual Competition between the Basal Ganglia and the Cortex
}

\author{
(1) Meropi Topalidou, ${ }^{1,2,3,4^{\dagger}}$ Daisuke Kase, ${ }^{2,3,5^{\dagger}} \oplus^{-}$Thomas Boraud, ${ }^{2,3,5,6^{\ddagger}}$ and $\bigodot^{-N i c o l a s ~ P . ~ R o u g i e r ~}{ }^{1,2,3,4^{\ddagger}}$
}

https://doi.org/10.1523/ENEURO.0339-17.2018

${ }^{1}$ INRIA Bordeaux Sud-Ouest, Talence 33405, France, ${ }^{2}$ Institut des Maladies Neurodégénératives, Université de Bordeaux, Bordeaux 33000, France, ${ }^{3}$ Institut des Maladies Neurodégénératives, Centre National de la Recherche Scientifique, Unité Mixte de Recherche 5293, Bordeaux 33000, France, ${ }^{4}$ Laboratoire Bordelais de Recherche en Informatique, Institut Polytechnique de Bordeaux, Centre National de la Recherche Scientifique, Unité Mixte de Recherche 5800, Université de Bordeaux, Bordeaux 33405, France, ${ }^{5}$ Centre National de la Recherche Scientifique, French-Israeli Neuroscience Lab, Bordeaux 33000, France, and ${ }^{6}$ Centre Hospitalier Universitaire de Bordeaux, Institut MN Clinique, Bordeaux 33000, France

\begin{abstract}
We propose a model that includes interactions between the cortex, the basal ganglia (BG), and the thalamus based on a dual competition. We hypothesize that the striatum, the subthalamic nucleus (STN), the internal globus pallidus (GPi), the thalamus, and the cortex are involved in closed feedback loops through the hyperdirect and direct pathways. These loops support a competition process that results in the ability of BG to make a cognitive decision followed by a motor one. Considering lateral cortical interactions, another competition takes place inside the cortex allowing the latter to make a cognitive and a motor decision. We show how this dual competition endows the model with two regimes. One is driven by reinforcement learning and the other by Hebbian learning. The final decision is made according to a combination of these two mechanisms with a gradual transfer from the former to the latter. We confirmed these theoretical results on primates (Macaca mulatta) using a novel paradigm predicted by the model.
\end{abstract}

Key words: covert learning; decision making; Hebbian learning; primate; reinforcement learning; theoretical approach

\section{Significance Statement}

In this article, we propose a detailed computational model of interaction between basal ganglia (BG) and cortex, in which the former adapts its response according to the outcome while the latter is insensitive to it. The model shows how these two processes interact to issue a unique behavioral answer. This prediction has been verified on monkeys, demonstrating how these two processes are both competing (expression) and cooperating (learning). These results suggest that a behavioral decision emerges actually from a dual competition of two distinct but entangled systems.

\section{Introduction}

Action-outcome (A-O) and stimulus-response (S-R) processes, two forms of instrumental conditioning, are important components of behavior. The former evaluates the benefit of an action to choose the best one among those available (action selection), while the latter is responsible for automatic behavior (routines), eliciting a response as soon as a known stimulus is presented
Received October 3, 2017; accepted November 16, 2018; First published December 12, 2018.

T.B. is a regular staff member the Centre National de la Recherche Scientifique, and N.R. is a regular staff member of Institut National de la Recherche en Informatique (INRIA). All other authors declare no competing financial interests.
Author contributions: T.B. and N.P.R. designed research; M.T. and D.K. performed research; M.T. and D.K. analyzed data; T.B. and N.P.R. wrote the paper.

This work was supported by the Agence Nationale pour la Recherche Grant ANR-09-SYSC-002-03 and the Centre National pour la Recherche Scientifique 
(Mishkin et al., 1984; Graybiel, 2008), independently of the hedonic value of the stimulus. Action selection can be easily characterized by using a simple operant conditioning setup, such as a two-armed bandit task, where an animal must choose between two options of different value, the value being probability, magnitude, or quality of reward (Pasquereau et al., 2007; Guthrie et al., 2013). After some trial and error, a wide variety of vertebrates are able to select the best option (Herrnstein, 1974; Graft et al., 1977; Bradshaw et al., 1979; Matthews and Temple, 1979; Dougan et al., 1985; Herrnstein et al., 1989; Lau and Glimcher, 2005, 2008; Gilbert-Norton et al., 2009). After intensive training, which depends on the species and the task and whether the same values are used throughout the series of the experiments, the animal will tend to become insensitive to change and persist in selecting the formerly best option (Lau and Glimcher, 2005; Yin and Knowlton, 2006). Most of the studies on action selection and habits/ routines agree on a slow and incremental transfer from the A-O to the S-R system such that after extensive training, the S-R system takes control of behavior, and the animal becomes insensitive to reward devaluation (Packard and Knowlton, 2002; Seger and Spiering, 2011). Oddly enough, very little is known on the exact mechanism underlying such transfer. One difficult question that immediately arises is when and how the brain switches from a flexible action selection system to a more static one.

Our working hypothesis is that there is no need for such an explicit switch. We propose instead that an action expressed in the motor area results from both the continuous cooperation (acquisition) and competition (expression) of the two systems. To do so, we consider the now classical actor-critic model of decision-making elaborated in the 1980s, which posits that there are two separate components to explicitly represent the policy independently from the value function. The actor is in charge of choosing an action in a given state (policy), while the critic is in charge of evaluating (criticizing) the current state (value function). This classical view has been used extensively for modeling the basal ganglia (BG; Suri and Schultz, 1999; Suri, 2002; Frank, 2004; Doya, 2007; Glimcher, 2011; Doll et al., 2012), although the precise anatomic mapping of these two processes is still subject to debate and may diverge from one model to the other (Redgrave et al., 2008; Niv and Langdon, 2016). However, all these models share the implicit assumption that the actor and the critic are interacting, i.e., the actor determines the policy exclusively from the values estimated by

(CNRS). The Laboratory of Excellency BRAIN supported the Primate Research Platform. M.T. was supported by a grant from INRIA (14333-2012). D.K. was supported by the Uehara Memorial Foundation and a fellowship from the French government.

${ }^{\dagger}$ M.T. and D.K. contributed equally to this work.

${ }^{\ddagger}$ T.H. and N.P.R. contributed equally to this work.

Correspondence should be addressed to Nicolas P. Rougier, E-mail: nicolas.rougier@inria.fr.

https://doi.org/10.1523/ENEURO.0339-17.2018

Copyright (C) 2018 Topalidou et al.

This is an open-access article distributed under the terms of the Creative Commons Attribution 4.0 International license, which permits unrestricted use, distribution and reproduction in any medium provided that the original work is properly attributed. the critic, as in Q-Learning or SARSA. Interestingly enough, Sutton and Barto (1998) noted in their seminal work that one could imagine intermediate architectures in which both an action-value function and an independent policy would be learned.

We support this latter hypothesis based on a decisionmaking model that is grounded on anatomic and physiologic data and that identify the cortex-BG (CBG) loop as the actor. The critic, of which the substantia nigra pars compacta (SNc) and the ventral tegmental area (VTA) are essential components, interacts through dopamine projections to the striatum (Leblois et al., 2006). Decision is generated by symmetry breaking mechanism that emerges from competitions processes between positives and negatives feedback loop encompassing the full CBG network (Guthrie et al., 2013). This model captured faithfully behavioral, electrophysiological, and pharmacological data we obtained in primates using implicit variant of twoarmed bandit tasks that assessed both learning and decision-making, but was less consistent with the explicit version (i.e., when values are known from the beginning of the task) that focus on the decision process only.

We therefore modified this early model by adding a cortical module that has been granted with a competition mechanism and Hebbian learning (Doya, 2000). This improved version of the model predicts that the whole CBG loop is actually necessary for the implicit version of the task; however, when the BG feedback to the cortex is disconnected, the system is nonetheless able to make a decision in the explicit version of the task. Our experimental data fully confirmed this prediction (Piron et al., 2016) and allowed us to solve an old conundrum concerning the pathophysiology of the BG: a lesion or jamming of the output of the BG improve Parkinson patient motor symptoms while it affects marginally their cognitive and psychomotor performances.

An interesting prediction of this generalized actor-critic architecture is that the valuation of options and the behavioral outcome are segregated. In the computational model, it is implied that if we block the output of the BG in a two-armed bandit task before learning, this should induce covert learning during the random choices of the model, because reinforcement learning should still occur at the striatal level under dopaminergic control. The goal of this study is thus two-fold: (1) to present a comprehensive description of the model to provide the framework for an experimental paradigm that allows to disclose covert learning, and (2) to test this prediction in monkeys.

\section{Materials and Methods}

\section{The task}

We consider a variant of a $n$-armed bandit task (Katehakis and Veinott, 1987; Auer et al., 2002) where a player must decide which arm of $n$ slot machines to play in a finite sequence of trials to maximize his accumulated reward. This task has received much attention in the literature (e.g., machine learning, psychology, biology, game theory, economics, neuroscience, etc.), because it provides a simple model to explore the trade-off between exploration (trying out a new arm to collect information 
Trial 1

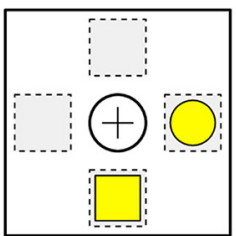

Trial 2

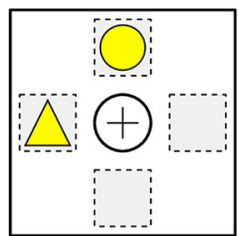

Trial 3

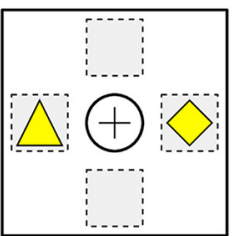

Cue set

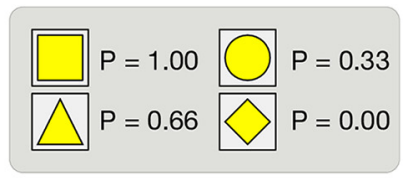

Figure 1. Three task trials from a four-item cue set $(\square, \bigcirc, \Delta, \diamond)$ with respective reward probabilities $(1,0.33,0.66$, and 0$)$.

about its payoff) and exploitation (playing the arm with the highest expected payoff; Robbins, 1952; Gittins, 1979). This task has been shown to be solvable for a large number of different living beings, with a brain (Plowright and Shettleworth, 1990; Keasar, 2002; Steyvers et al., 2009) or without a brain (Reid et al., 2016), and even a clever physical apparatus can solve the task (Naruse et al., 2015).

\section{The computational task}

In the present study, we restrict the $n$-armed bandit task to $n=2$ with an explicit dissociation between the choice of the option (cognitive choice) and the actual triggering of the option (motor choice). This introduces a supplementary difficulty because only the motor choice, the physical (and visible) expression of the choice, will be taken into account when computing the reward. If cognitive and motor choices are incongruent, only the motor choices matter. Unless specified otherwise, we consider a set of cues $\left\{C_{i}\right\}_{\mathrm{i} \in[1, n]}$ associated with reward probabilities $\left\{P_{i}\right\}_{i \in[1, n]}$ and a set of four different locations $\left(\left\{L_{i}\right\}_{i \in[1,4]}\right)$ corresponding to the up, down, left, and right positions on the screen. A trial is made of the presentation of two random cues $C_{i}$ and $C_{i}(i \neq j)$ at two random locations $\left(L_{i}\right.$ and $\left.L_{j}\right)$ such that we have $L_{i} \neq L_{i}$ (Fig. 1). A session is made of $n$ successive trials and can use one to several different cue sets depending on the condition studied (e.g., reversal, devaluation). Unless specified otherwise, in the present study, exactly one cue set is used throughout a whole session.

Once a legal motor decision has been made (i.e., a motor action corresponding to one of the stimulus position), the reward is computed by drawing a random uniform number between 0 and 1 . If the number is less or equal to the reward probability of the chosen cue, a reward of 1 is given, otherwise, a reward of 0 is given. If no motor choice has been made or if the motor choice leads to an empty location (illegal choice), the trial is considered to be failed and no reward is given, which is different from giving a reward of 0 . The best choice for a trial is defined as the choice of the cue associated with the highest reward probability among the two presented cues. Performance is defined as the ratio of best choices over the total number of trials. A perfect player with full-knowledge can achieve a performance of 1 while the mean expectation of the reward is directly dependent on the cue sampling policy. For example, in Figure 1, if we consider a uniform cue sampling policy for $6 * n$ trials, the mean expected reward for a perfect player with full knowledge is $3 / 6 \times 1+2 / 6 \times 2 / 3+1 / 6 \times 1 / 3=14 / 18 \approx 0.777 .$. ).

\section{The behavioral task}

With kind permission from the authors (Piron et al., 2016), we reproduce here the details of the experimental task which is similar.

The primates were trained daily in the experimental room and familiarized with the setup, which consisted of four buttons placed on a board at different locations $\left(0^{\circ}\right.$, $90^{\circ}, 180^{\circ}$, and $270^{\circ}$ ), and a further button in a central position, which detects contact with a monkey's hand. These buttons correspond to the four possible display positions of a cursor on a vertical screen. The monkeys were seated in chairs in front of this screen at a distance of $50 \mathrm{~cm}$ (Fig. 2). The monkeys initiated a trial by keeping their hands on the central button, which induced the appearance of the cursor in the central position of the screen. After a random delay (0.5-1.5 s), two cues appeared in two (of four) different positions determined randomly for each trial. Each cue had a fixed probability of reward $\left(p_{1}=0.75\right.$ and $\left.p_{2}=0.25\right)$ and remains the same during a session. Once the cues were shown, the monkeys had a random duration time window $(0.5-1.5 \mathrm{~s})$ to press the button associated with one cue. It moves the cursor over the chosen cue and they have to maintain the position for $0.5-1.5 \mathrm{~s}$. After this delay, the monkeys were rewarded $(0.3 \mathrm{ml}$ of water) or not according to the reward probability of the chosen target. The disappearance of the cursor corresponds to an end-of-trial signal, indicating to the monkeys that the trial was finished and they could start a new trial after an intertrial interval between 0.5 and $1.5 \mathrm{~s}$.

\section{The model}

The model is designed to study the implications of a dual competition between the cortex and the BG. It is segregated into three territories partially overlapping at the striatal level (for full discussion, see Guthrie et al., 2013). The motor territory elicits the actual behavioral choice of the model by selecting one of the two positions in which the cues are presented. It roughly corresponds to the supplementary motor area and associated subcortical territories. The cognitive loop chooses one of the two cues that are displayed roughly corresponding to the role devoted to the dorsal lateral prefrontal cortex and associated subterritories. The associative cortex provides a contextual map indicating which cue is presented where on each trial and roughly correspond to the parietal cortex. While in the animal we have access only to the actual choice (provided by the actual behavior of the animal), the model allowed us to have access to the internal choice by looking at which of the 


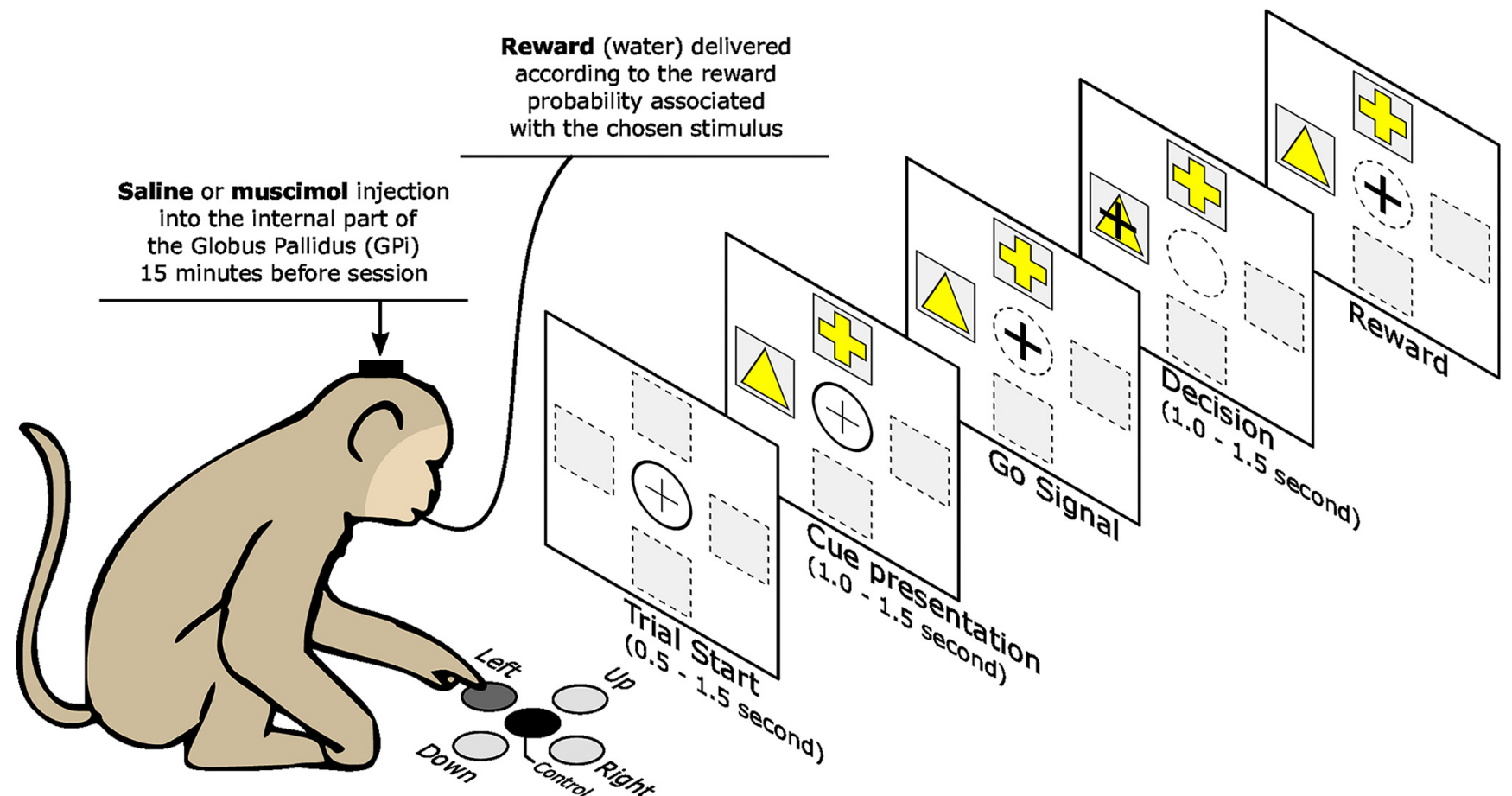

Figure 2. Behavioral task. The monkeys initiate a trial by keeping their hands on the central button, which induced the appearance of the cursor in the central position of the screen. After a random delay, two cues appear in two different positions. The monkey has a random duration time window $(0.5-1.5 \mathrm{~s})$ to press the button associated with one cue. It moves the cursor over the chosen cue and has to maintain the position for some duration. After this delay, the monkey is rewarded ( $0.3 \mathrm{ml}$ of water) or not according to the reward probability of the chosen cue.

two cues was selected at each trial. It could happen that the cognitive loop chooses one cue, while the motor loop chooses the position of the other one, especially at the beginning of the trial, when the synaptic signal-to-noise is still week due to low gain. This cognitive dissonance maybe a mechanism for impulsivity, but it is beyond the scope of this paper.

The competition inside the cortex is conveyed through direct lateral interactions using short-range excitation and long-range inhibition (Wilson and Cowan, 1972, 1973; Coultrip et al., 1992; Deco et al., 2014; Muir and Cook, 2014), while the competition within the $B G$ is conveyed through the direct and hyperdirect pathways (Leblois et al., 2006; Guthrie et al., 2013). Therefore, the indirect pathway and the external segment of the globus pallidus (GPe) are not included. to solve the task, the model relies on the competition between diverging negative feedback loops that provide lateral inhibition, and parallel positive feedback loops that promote differential activation allowing the issue of different cognitive and motor choices. This competitive mechanism occurs at both the basal and cortical level, but the final decision is derived from the cortical level. As soon as the motor cortex activity is above a given threshold, the model is considered to have made a decision. In contrast to (Gurney et al., 2001; Frank, 2004; Doya, 2007), our model relies heavily on feedback mechanisms and closed loops while the latter are purely feed-forward models that merely answer to inputs.

\section{Architecture}

Our model contains five main groups. Three of these groups are excitatory: the cortex, the thalamus, and the subthalamic nucleus (STN). Two populations are inhibitory corresponding to the sensorimotor territories of the striatum and the internal globus pallidus (GPi). The model has been further tailored into three segregated loops (Alexander et al., 1986; Alexander and Crutcher, 1990; Alexander et al., 1991; Mink, 1996; Haber, 2003), namely the motor loop, the associative loop and the cognitive (or limbic) loop. The motor loop comprises the motor cortex (supplementary motor area, primary cortex, premotor cortex, cingulate motor area), the motor striatum (putamen), the motor STN, the motor GPI (motor territory of the pallidum and the substantia nigra), and the motor thalamus (ventrolateral thalamus). The associative loop comprises the associative cortex (dorsolateral prefrontal cortex, the lateral orbitofrontal cortex) and the associative striatum (associative territory of the caudate). The cognitive loop comprises the cognitive cortex (anterior cingulate area, medial orbitofrontal cortex), the cognitive striatum (ventral caudate), the cognitive STN, the cognitive GPi (limbic territory of the pallidum and the substantia nigra), and the cognitive thalamus (ventral anterior thalamus).

\section{Populations}

The model consists of 12 populations: five motor, four cognitive, and two associative populations (Fig. 3). These populations comprise from four to 16 neural assemblies and each possesses a specific geometry whose goal is to facilitate connectivity description. Each assembly is 


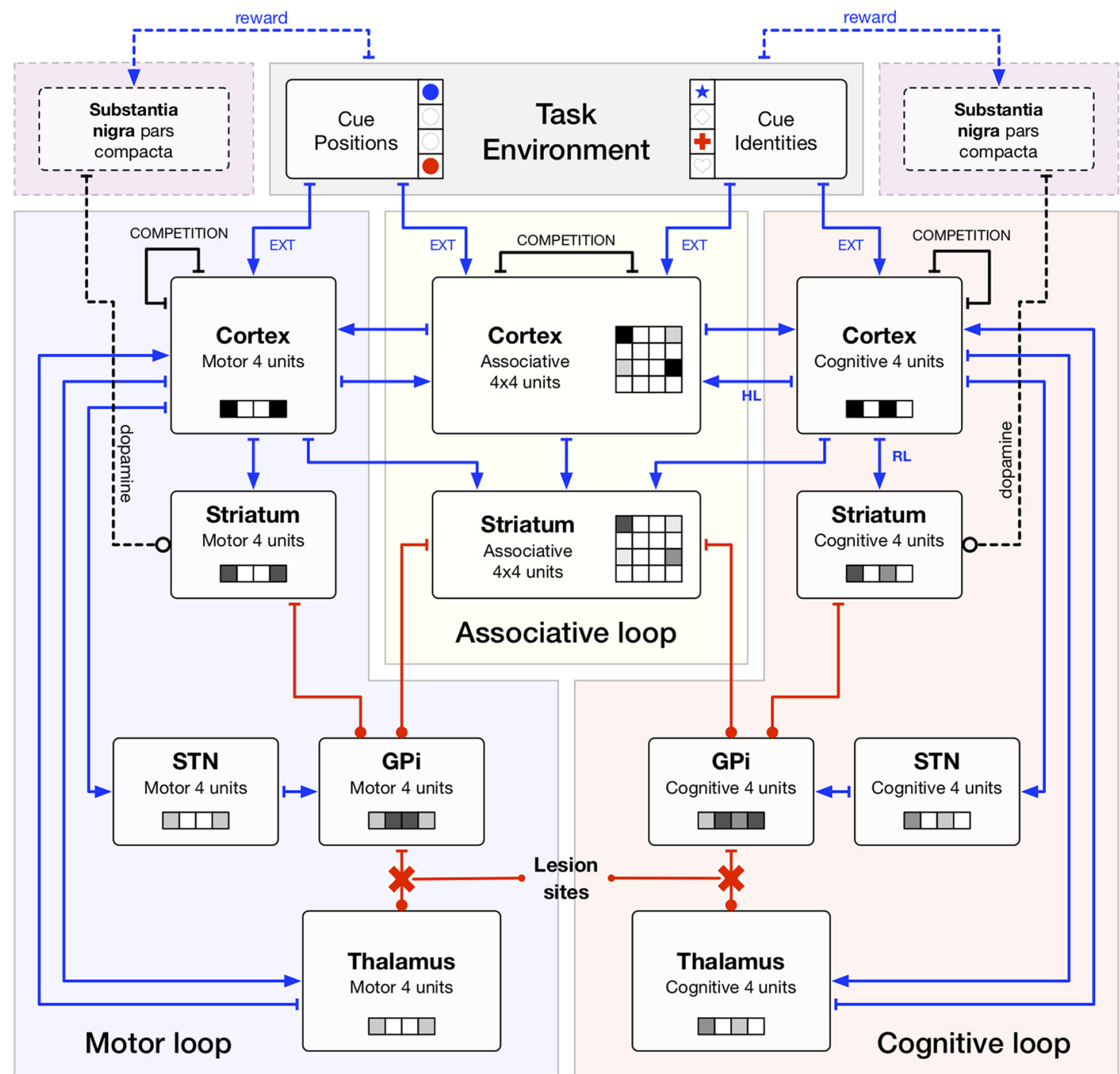

Figure 3. Architecture of the model. The architecture of the model is centered around the hyperdirect pathway (cortex $\rightarrow$ STN $\rightarrow$ $\mathrm{GPi} / \mathrm{SNR} \rightarrow$ thalamus $\rightarrow$ cortex), the direct pathway (cortex $\rightarrow$ striatum $\rightarrow \mathrm{GPi} / \mathrm{SNR} \rightarrow$ thalamus $\rightarrow$ cortex) and the cortex where lateral interactions take place. The model is further detailed into three segregated circuits (cognitive, associative, motor). The cognitive and motor circuit each comprises a cortical, a striatal, a thalamic, a subthalamic, and a pallidal population while the associative loop only comprises a cortical and a striatal population. This latter interacts with the two other circuits via diffused connections to the pallidal regions and from all cortical populations. Arrows, excitatory connections. Dots, inhibitory connections.

modeled using a neuronal rate model (Hopfield, 1984; Shriki et al., 2003) that give account of the spatial mean firing rate of the neurons composing the assembly. Each assembly is governed by the following equations:

$$
\begin{gathered}
\tau \frac{d V}{d t}=-V+I_{\text {syn }}+I_{\text {ext }}+h \\
U=f(V+V . n)
\end{gathered}
$$

where $\tau$ is the assembly time constant (decay of the synaptic input), $V$ is the firing rate of the assembly, $I_{\text {syn }}$ is the synaptic input to the assembly, $l_{\text {ext }}$ is the external input representing the sensory visual salience of the cue, $h$ is the threshold of the assembly, $f$ is the transfer function and $n$ is the (correlated, white) noise term. Each population possess its own set of parameters according to the group it belongs to
(Table 1). Transfer function for all population but the striatal population is a ramp function $[f(x)=\max (x, 0)]$. The striatal population that is silent at rest (Sandstrom and Rebec, 2003), requires concerted coordinated input to cause firing (Wilson and Groves, 1981), and has a sigmoidal transfer function (nonlinear relationship between input current and membrane potential) due to both inward and outward potassium current rectification (Nisenbaum and Wilson, 1995). This is modeled by applying a sigmoidal transfer function to the activation of cortico-striatal inputs in the form of the Boltzmann equation:

$$
f(x)=V_{\text {min }}+\frac{V_{\max }-V_{\min }}{1+e^{\frac{V_{h}-x}{V_{c}}}}
$$

where $V_{\min }$ is the minimum activation, $V_{\max }$ the maximum activation, $V_{h}$ the half- activation, and $V_{c}$ the slope. This is 
Table 1 Population parameters

\begin{tabular}{llllll}
\hline Population & & Geometry & $\tau$ & Threshold & Noise \\
Cortex & Associative & $(4,4)$ & $10 \mathrm{~ms}$ & -3 & $1.0 \%$ \\
& Cognitive & $(4,1)$ & $10 \mathrm{~ms}$ & -3 & $1.0 \%$ \\
\multirow{5}{*}{ Striatum } & Motor & $(1,4)$ & $10 \mathrm{~ms}$ & -3 & $1.0 \%$ \\
& Associative & $(4,4)$ & $10 \mathrm{~ms}$ & 0 & $0.1 \%$ \\
& Cognitive & $(4,1)$ & $10 \mathrm{~ms}$ & 0 & $0.1 \%$ \\
GPi & Motor & $(4,1)$ & $10 \mathrm{~ms}$ & 0 & $0.1 \%$ \\
\multirow{5}{*}{ STN } & Cognitive & $(4,1)$ & $10 \mathrm{~ms}-10$ & $3.0 \%$ \\
\multirow{5}{*}{ Thalamus } & Motor & $(1,4)$ & $10 \mathrm{~ms}-10$ & $3.0 \%$ \\
& Cognitive & $(4,1)$ & $10 \mathrm{~ms}-10$ & $0.1 \%$ \\
& Motor & $(1,4)$ & $10 \mathrm{~ms}-10$ & $0.1 \%$ \\
& Cognitive & $(4,1)$ & $10 \mathrm{~ms}-40$ & $0.1 \%$ \\
& Motor & $(1,4)$ & $10 \mathrm{~ms}-40$ & $0.1 \%$ \\
\hline
\end{tabular}

similar to the use of the output threshold in the (Gurney et al., 2001) model and results in small or no activation to weak inputs with a rapid rise in activation to a plateau level for stronger inputs. The parameters used for this transfer function are shown in Table 2 and were selected to give a low striatal output with no cortical activation (1 spike/s), starting to rise with a cortical input of 10 spikes/s and a striatal output of 20 spikes/s at a cortical activation of 30 spikes/s.

\section{Connectivity}

Although the model takes advantage of segregated loops, they cannot be entirely separated if we want the cognitive and the motor channel to interact. This is the reason why we incorporated a divergence in the corticostriatal connection followed by a re-convergence within the GPi (Graybiel et al., 1994; Parent et al., 2000; Fig. 4). Furthermore, we considered the somatotopic projection of the pyramidal cortical neurons to the striatum (Webster, 1961) as well as their arborization (Wilson, 1987; Parthasarathy et al., 1992; Cowan and Wilson, 1994; Parent et al., 2000) resulting in specific localized areas of button formation (Kincaid et al., 1998) and small cortical areas innervating the striatum in a discontinuous pattern with areas of denser innervation separated by areas of sparse innervation (Flaherty and Graybiel, 1991; Brown et al., 1998). We also considered the large reduction in the number of neurons from cortex to striatum to GPi (Oorschot, 1996; Bar-Gad and Bergman, 2001). These findings combined lead to striatal areas that are mostly specific for input from one cortical area alongside areas where there is overlap between inputs from two or more cortical areas (Takada et al., 2001) and which are here referred to as the associative striatum.

The gain of the synaptic connection from population $A$ (presynaptic) to population $B$ (postsynaptic) is denoted as $G_{A \rightarrow B}$, and the total synaptic input to population B is:

Table 2 Parameters for striatal sigmoid transfer function

\begin{tabular}{ll}
\hline$N a m e$ & Value \\
$V_{\min }$ & 1 \\
$V_{\max }$ & 20 \\
$V_{h}$ & 16 \\
$V_{c}$ & 3 \\
\hline
\end{tabular}

$$
I_{\text {syn }}^{B}=G_{A \rightarrow B} \sum_{A} U_{A}
$$

where $A$ is the presynaptic assembly, $B$ is the postsynaptic assembly, and $U_{A}$ is the output of presynaptic assembly $A$. The gains for each pathway are shown in Table 3 . Gains to the corresponding cognitive (motor) assembly are initially five times higher than to each receiving associative area. Reconvergence from cognitive (motor) and association areas of striatum to cognitive (motor) areas of GPi are evenly weighted.

\section{Task encoding}

At the trial start, assemblies in the cognitive cortex encoding the two cues, $C_{1}$ and $C_{2}$, receive an external current $(7 \mathrm{~Hz})$ and assemblies in the motor cortex encoding the two positions, $M_{1}$ and $M_{2}$, receive a similar external current $(7 \mathrm{~Hz})$. These activities are ambiguous since they could mean $\left[C_{1} / M_{1}, C_{2} / M_{2}\right]$ or $\left[C_{1} / M_{2}, C_{2} / M_{1}\right]$ (binding problem). This is the reason why the associative cortex encoding one of these two situations receives an external current $(7 \mathrm{~Hz}),\left(C_{1} / M_{1}, C_{2} / M_{2}\right)$ that allows to bind a stimulus with a position (Fig. 5). The decision of the model is decoded from the activity in the motor cortex only, i.e., independently of the activity in the cognitive cortex. If the model chooses a given cue but produces the wrong motor command, the cognitive choice will not be taken into account, and the final choice will be decoded from the motor command, although that it may lead to an irrelevant choice.

\section{Dynamics}

Two different competition mechanisms exist inside the model. One is conveyed through the direct and hyperdirect pathways, the other is conveyed inside the cortex through short-range excitation and long-range inhibition. The former has been fully described and analyzed in Leblois et al. (2006), while the latter been extensively studied in a number of experimental and theoretical papers (Wilson and Cowan, 1972, 1973; von der Malsburg, 1973; Amari, 1977; Callaway, 1998; Taylor, 1999). Each of these two competition mechanisms can lead to a decision as illustrated in Figure 6, which shows the dynamic of the motor loop for all the population in three conditions. In the absence of the cortical interactions (gain of cortical lateral connections has been set to 0 ), the direct and hyperdirect pathway are able to promote a competition that results in the selection of one of the two assemblies in each group. In the absence of GPi output (connection has been cut), the cortical lateral connections are able to support a competition resulting in the selection of one of the two assemblies, although such decision is generally slower than decisions formed in the BG. The result of the dual competition is a faster selection of one of the two assemblies after learning, when there is no possibility for the two competitions to be non-congruent (one competition tends to select move A while the others tend to select move B). We will see in the results section that if the result of the two competitions is non-congruent, the decision is slower. 

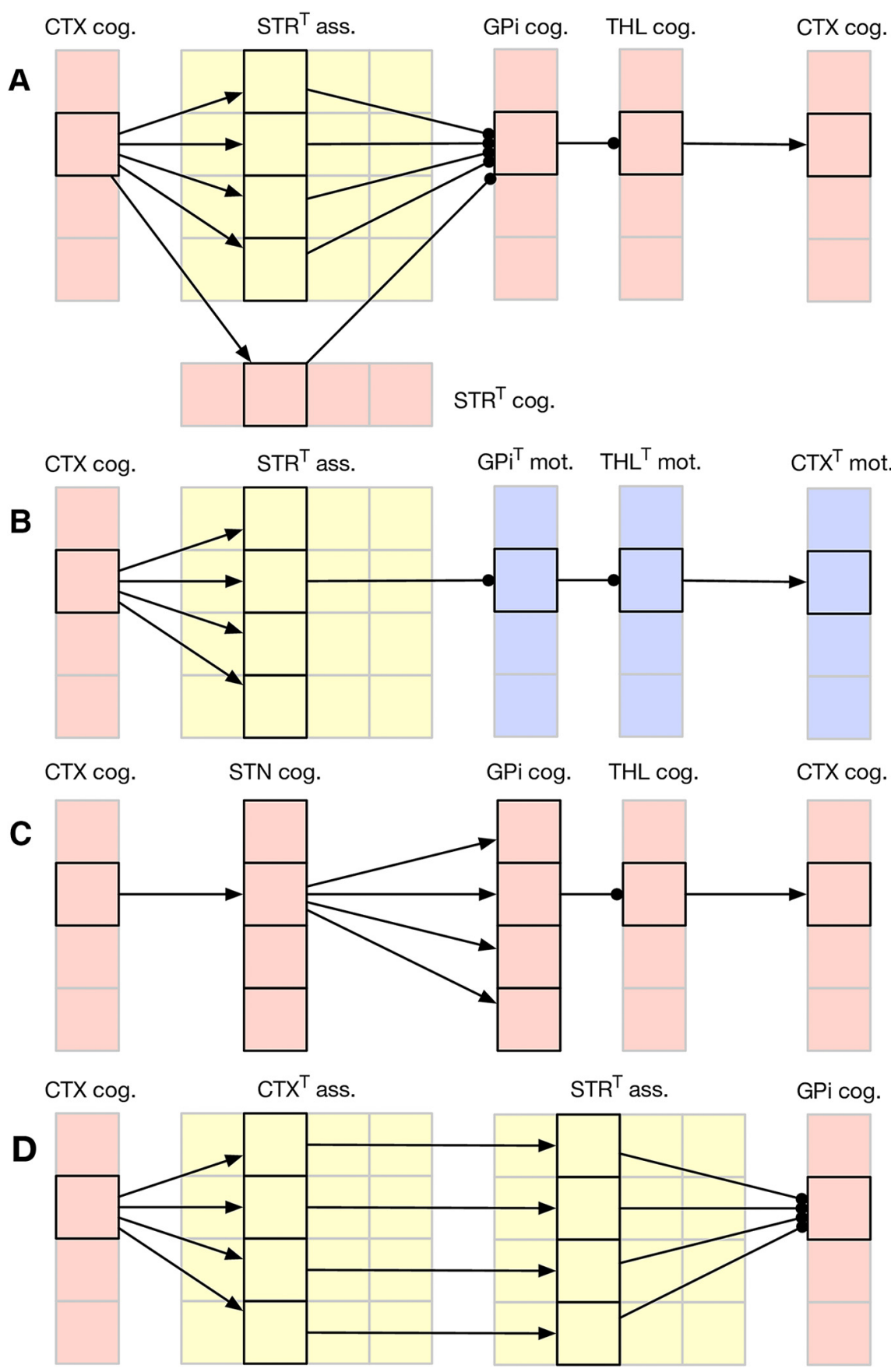

Figure 4. Partial connectivity in the cognitive and associative loops. For clarity, only one assembly has been considered. The motor loop is symmetric to the cognitive one. The T symbol on some name means the geometry of the group has been transposed (for readability). $\boldsymbol{A}$, The direct pathway from cognitive cortical assemblies diverge from cortex to associative and cognitive striatum. The pathway converges into cognitive GPi, sends parallel projection to the thalamus, and forms a closed loop with the original cognitive cortical assembly. $\boldsymbol{B}$, Thanks to the convergence of motor and cognitive pathways in associative striatum, there is a cross talk between the motor and cognitive loops. This allows a decision to be made in the cognitive loop to influence the decision in motor loops and vice versa. $\boldsymbol{C}$, The hyperdirect pathway from cognitive cortical assembly diverges from STN to GPi, innervating all cognitive, but not motor, GPi regions and feeds back to all cognitive cortical assemblies. $\boldsymbol{D}$, The pathway from associative cortex and associative striatum is made of parallel localized projections.

\section{Learning}

Learning has been restricted to the cognitive channel on the cortico-striatal synapse (between the cognitive cortex and striatum) and the corticocortical synapses (between the cognitive and associative cortex). Most proba- bly there is learning in other structures and pathways, but the aim here is to show that the proposed restriction is sufficient to produce the behavior under consideration. All synaptic weights are initialized to 0.5 (SD, 0.005) and used as a multiplier to the pathway gain to keep the factors of 
Table 3 Connectivity gains and pattern between the different populations

\begin{tabular}{|c|c|c|c|c|}
\hline Pop. A & Pop. B & Pathway & Pattern & Gain \\
\hline \multirow[t]{4}{*}{ Cortex } & Striatum & cog. $\rightarrow$ cog. $\cdot$ & $(\mathrm{i}, 1) \rightarrow(\mathrm{i}, 1)$ & 1.0 \\
\hline & & mot. $\rightarrow$ mot. & $(i, 1) \rightarrow(i, 1)$ & 1.0 \\
\hline & & ass. $\rightarrow$ ass. & $(i, j) \rightarrow(i, j)$ & 1.0 \\
\hline & & cog. $\rightarrow$ ass. & $(\mathrm{i}, 1) \rightarrow(\mathrm{i}, *)$ & 0.2 \\
\hline \multicolumn{5}{|c|}{ mot. $\rightarrow$ ass. $(1, \mathrm{i}) \rightarrow(*, \mathrm{i}) 0.2$} \\
\hline STN & & cog. $\rightarrow$ cog. & $(\mathrm{i}, 1) \rightarrow(\mathrm{i}, 1)$ & 1.0 \\
\hline \multicolumn{5}{|c|}{ mot. $\rightarrow$ mot. $(1, i) \rightarrow(1, i) 1.0$} \\
\hline Thalamus & & cog. $\rightarrow$ cog. & $(\mathrm{i}, 1) \rightarrow(\mathrm{i}, 1)$ & 0.1 \\
\hline \multicolumn{5}{|c|}{ mot. $\rightarrow$ mot. $(1, i) \rightarrow(1, i) 0.1$} \\
\hline Cortex & & cog. $\rightarrow$ cog. & $(\mathrm{i}, 1) \rightarrow(*, 1)$ & \pm 0.5 \\
\hline & & mot. $\rightarrow$ mot. & $(1, i) \rightarrow(1, *)$ & \pm 0.5 \\
\hline & & ass. $\rightarrow$ ass. & $(\mathrm{i}, \mathrm{j}) \rightarrow(*, *)$ & \pm 0.5 \\
\hline & & ass. $\rightarrow$ mot. & $(*, \mathrm{i}) \rightarrow(1, \mathrm{i})$ & 0.025 \\
\hline & & ass. $\rightarrow$ cog. & $(\mathrm{i}, *) \rightarrow(\mathrm{i}, 1)$ & 0.01 \\
\hline & & cog. $\rightarrow$ ass. & $(\mathrm{i}, 1) \rightarrow(\mathrm{i}, *)$ & 0.025 \\
\hline \multicolumn{5}{|c|}{ mot. $\rightarrow$ ass. $(1, i) \rightarrow(*, i) 0.01$} \\
\hline Striatum & GPi & cog. $\rightarrow$ cog. & $(\mathrm{i}, 1) \rightarrow(\mathrm{i}, 1)$ & -2.0 \\
\hline & & mot. $\rightarrow$ mot. & $(1, \mathrm{i}) \rightarrow(1, \mathrm{i})$ & -2.0 \\
\hline & & ass. $\rightarrow$ cog. & $(\mathrm{i}, *) \rightarrow(\mathrm{i}, 1)$ & -2.0 \\
\hline \multicolumn{5}{|c|}{ ass. $\rightarrow$ mot. $(*, i) \rightarrow(1, i)-2.0$} \\
\hline STN & GPi & cog. $\rightarrow$ cog. & $(\mathrm{i}, 1) \rightarrow(\mathrm{i}, 1)$ & 1.0 \\
\hline \multicolumn{5}{|c|}{ mot. $\rightarrow$ mot. $(1, \mathrm{i}) \rightarrow(1, \mathrm{i}) 1.0$} \\
\hline GPi & $\begin{array}{c}\text { Thalamus } \\
\text { mot. }\end{array}$ & \multicolumn{2}{|c|}{ mot. $\rightarrow$ mot. $(1, \mathrm{i}) \rightarrow(1, \mathrm{i})-1.0$} & -1.0 \\
\hline Thalamus & Cortex & cog. $\rightarrow$ cog. & $(\mathrm{i}, 1) \rightarrow(\mathrm{i}, 1)$ & 1.0 \\
\hline & & mot. $\rightarrow$ mot. & $(1, i) \rightarrow(1, i)$ & 1.0 \\
\hline
\end{tabular}

For connectivity patterns, * means all. For example, $(1, i) \rightarrow(1, *)$ means oneto-all connectivity, while $(1, \mathrm{i}) \rightarrow(1, \mathrm{i})$ means one-to-one connectivity. Plastic pathways are indicated by $\mathrm{a} \cdot$ symbol.

gain and weight separately observable. All weights are bound between $W$ min and Wmax (Table 4) such that for any change $\Delta W(t)$, weight $W(t)$ is updated according to the equation:

$$
W(t) \leftarrow W(t)+\Delta W(t)\left(W_{\max }-W(t)\right)\left(W(t)-W_{\min }\right)
$$

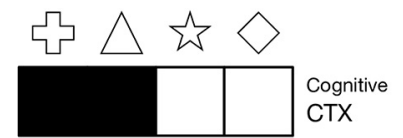

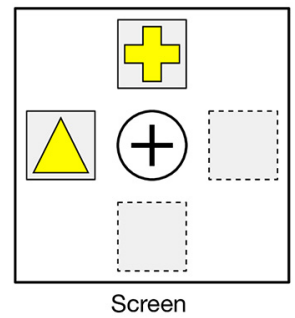
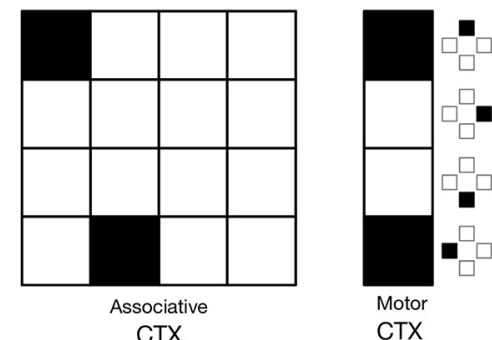

Figure 5. Task encoding. Assemblies in the cognitive cortex encoding the two cues, $C_{1}$ and $C_{2}$, receive an external current, and assemblies in the motor cortex encoding the two positions, $M_{1}$ and $M_{2}$, receive a similar external current. These activities are not sufficient to disambiguate between $\left[C_{1} / M_{1}, C_{2} / M_{2}\right]$ or $\left[C_{1} / M_{2}\right.$, $C_{2} / M_{1}$ ] (binding problem). This is the reason why the associative cortex encoding one of these two situations receives also an external current, $\left(C_{1} / M_{1}, C_{2} / M_{2}\right)$ to disambiguate the two cases, hence solving the binding problem.

\section{Reinforcement learning}

At the level of cortico-striatal synapses, phasic changes in dopamine concentration have been shown to be necessary for the production of long-term potentiation (LTP; Kerr and Wickens, 2001; Reynolds et al., 2001; Surmeier et al., 2007; Pawlak and Kerr, 2008). After each trial, once reward has been received ( 0 or 1 ), the cortico-striatal weights are updated according to the reward prediction error (RPE):

$$
\begin{gathered}
\Delta W_{B}^{A}=L T P_{R L} \times R P E \times U_{B} \text { if RPE }>0 \\
=L T D_{R L} \times R P E \times U_{B} \text { if } \mathrm{RPE}<0
\end{gathered}
$$

where $\Delta W_{B}^{A}$ is the change in the weight of the corticostriatal synapse from cortical assembly $A$ to striatal assembly $\mathrm{B}, R P E$ is the RPE, the amount by which the actual reward delivered differs from the expected reward, UB is the activation of the striatal assembly, and $\alpha$ is the actor learning rate. Generation of LTP and long-term depression (LTD) in striatal MSNs has been found to be asymmetric (Pawlak and Kerr, 2008). Therefore, in the model, the actor learning rate is different for LTP and LTD. The RPE is calculated using a simple critic learning algorithm:

$$
R P E=R-V_{\mathrm{i}}
$$

where $\mathrm{R}$, the reward, is 0 or 1 , depending on whether a reward was given or not on that trial. Whether a reward was given, it was based on the reward probability of the selected cue (which is the one associated with the direction that was chosen); $i$ is the number of the chosen cue, and $V_{i}$ is the value of cue $i$. The value of the chosen cue is then updated using the RPE:

$$
V_{i} \leftarrow V_{i}+\alpha R P E
$$

\section{Hebbian learning}

At the level of corticocortical synapses, only the coactivation of two assemblies is necessary for the production of LTP (Bear and Malenka, 1994; Caporale and Dan, 2008; Feldman, 2009; Hiratani and Fukai, 2016). After each trial, once a move has been initiated, the corticocortical weights are updated according to:

$$
\Delta W_{B}^{A}=L T P_{H L} \times U_{A} \times U_{B}
$$

where $\Delta W_{B}^{A}$ is the change in the weight of the corticocortical synapse from cognitive cortical assembly A to associative cortical assembly $\mathrm{B}$. This learning rule is thus independent of reward.

\section{Experimental setup}

Experimental data were obtained from two female macaque monkeys (Macaca mulatta). Experiments were performed during the daytime. Monkeys were living under a $12 / 12$ h light/dark diurnal rhythm. Although food access was available ad libitum, the primates were kept under water restriction to increase their motivation to work. A veterinary skilled in health care and maintenance in nonhuman primates supervised all aspects of animal care. 

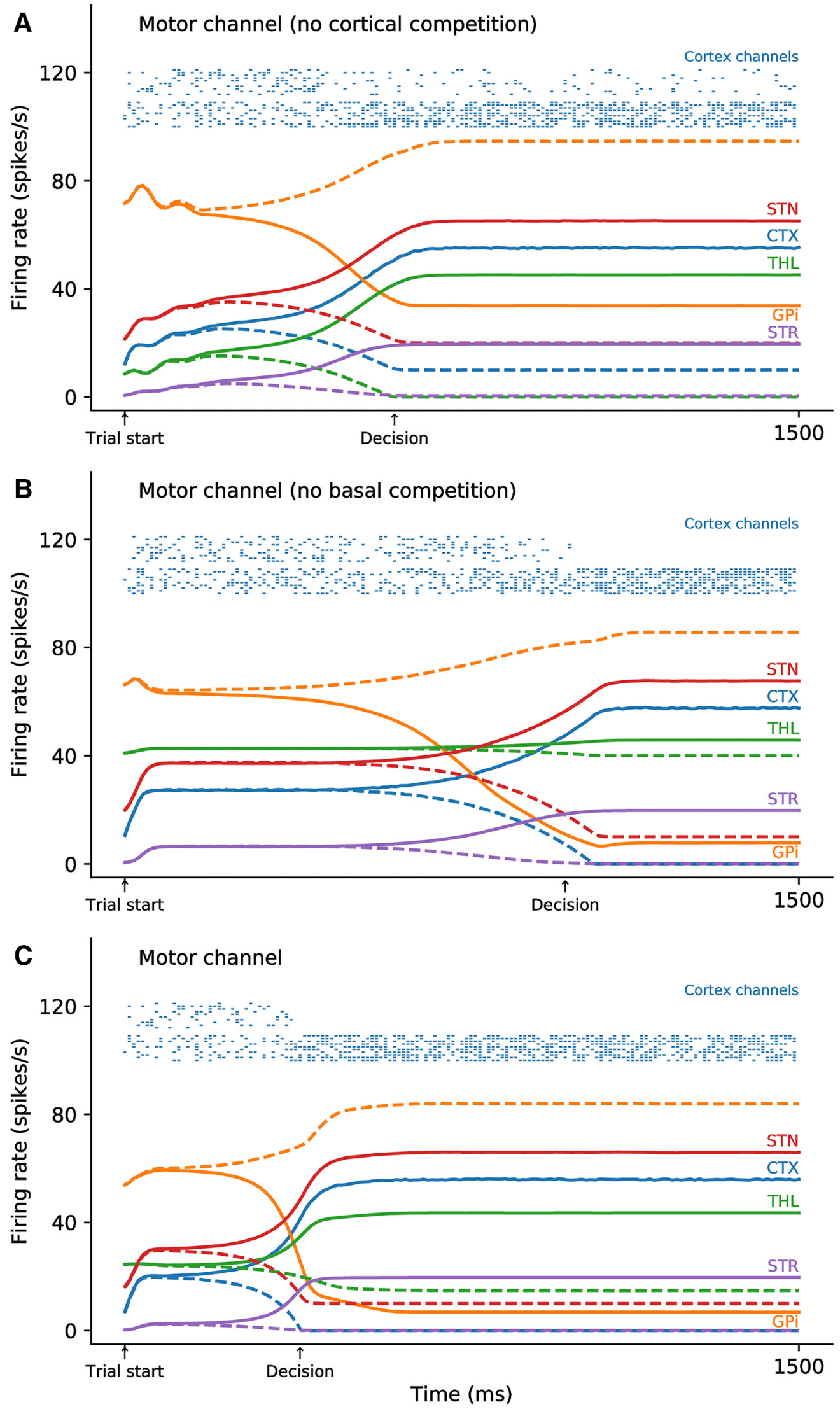

Figure 6. Activity in different populations during a single trial of action selection before learning. The trial starts at time $t=0 \mathrm{~ms}$, and the model is allowed to settle to a steady state until the presentation of the cues at $t=500 \mathrm{~ms}$. Solid lines represent activity related 


\section{continued}

to the selected population, dashed lines represent activity related to the non-selected population. Decision threshold has been set to $40 \mathrm{spikes/s}$ between the two cortical populations and is indicated on the $x$-axis. Raster plots are related to the cortical populations and has been generated from the firing rate of 10 neurons. A, Activity in the motor populations in the absence of lateral competition in the cortical populations. The damped oscillations during the settling phase are characteristic of the delayed feedback from the STN (excitation) and the striatum (inhibitory) through the globus pallidus and the thalamus. $\boldsymbol{B}$, Activity in the motor populations in the absence of the feedback from the BG (GPi) to the cortical populations via the thalamus. Decision threshold is reached thanks to the direct lateral competition in both cognitive and motor cortical channels. There is no damped oscillation, since there is no delay between the cortical populations, and the decision times are slower than in the previous case. $\boldsymbol{C}$, Activity in the motor populations in the full model with a dual competition, one cortical and one basal. When congruent (cortical and basal decision are the same), decision time for both the motor and cortical channels are faster than in the absence of one of the competition loop.

Experimental procedures were performed in accordance with the Council Directive of 20 October 2010 (2010/63/ UE) of the European Community. This project was approved by the French Ethic Committee for Animal Experimentation (50120111-A).

\section{Surgical procedure}

Cannula guides were implanted into the left and right GPi in both animals under general anesthesia. Implantation was performed inside a stereotaxic frame guided by ventriculography and single-unit electrophysiological recordings. A ventriculographic cannula was introduced into the anterior horn of the lateral ventricle and a contrast medium was injected. Corrections in the position of the GPi were performed according to the line between the anterior commissure (AC) and the posterior commissure (PC) line. The theoretical target was AP: $23.0 \mathrm{~mm}$, L: 7.0 $\mathrm{mm}, \mathrm{P}: 21.2 \mathrm{~mm}$. A linear 16-channel multielectrode array was lowered vertically into the brain. Extracellular singleunit activity was recorded from 0 to $24 \mathrm{~mm}$ relative to the AC-PC line with a wireless recording system. Penetration of the electrode array into the GPi was characterized by an increase in the background activity with the appearance of active neurons with a tonic firing rate (around the AC-PC line). The exit of the electrode tips from the GPi was characterized by the absence of spike (around 3-4 $\mathrm{mm}$ below the AC-PC line). When a clear GPi signal from at least three contacts had been obtained, control radiography of the position of the recording electrode was performed and compared to the expected position of the target according to the ventriculography. If the deviation from the expected target was less than $1 \mathrm{~mm}$, the electrode was removed and a cannula guide was inserted with a spare cannula inside so that the tip of the cannula was superimposed on the location of the electrode array in the control radiography. Once the cannula guide was satisfactorily placed, it was fixed to the skull with dental cement.

\section{Table 4 Learning parameters}

\begin{tabular}{ll}
\hline Name & Value \\
$W_{\min }$ & 0.25 \\
$W_{\max }$ & 0.75 \\
$L T P_{R L}$ & 0.050 \\
$L T D_{R L}$ & 0.030 \\
$L T P_{H L}$ & 0.005 \\
$\alpha$ & 0.025
\end{tabular}

\section{Bilateral inactivation of the GPi}

Microinjections were delivered bilaterally $15 \mathrm{~min}$ before a session. For both animals, injections of the $G A B A A$ agonist muscimol hydrobromide (Sigma) or saline ( $\mathrm{NaCl} 9$ ) were randomly assigned each day. Muscimol was delivered at a concentration of $1 \mu \mathrm{g} / \mu \mathrm{l}$ (dissolved in a $\mathrm{NaCl}$ vehicle). Injections ( $1 \mu \mathrm{l}$ in each side) were performed at a constant flow rate of $0.2 \mu \mathrm{l} / \mathrm{min}$ using a microinjection system. Injections were made through a 30-gauge cannula inserted into the two guide cannula targeting left and right GPi. Cannulas were connected to a $25-\mu$ l Hamilton syringe by polyethylene cannula tubing.

\section{Data analysis}

Theoretical and experimental data were analyzed using Kruskal-Wallis rank sum test between the three conditions [saline (CO), muscimol (C1) or saline following muscimol (C2)] for the six samples [12 $\times 10$ first trials of $\mathrm{CO}$ (control), $12 \times 10$ last trials of $\mathrm{CO}$ (control), $12 \times 10$ first trials of $\mathrm{C} 1$ (GPi Off/muscimol), $12 \times 10$ last trials of C1(GPi Off/ muscimol), $12 \times 10$ first trails of C2(GPi On/saline), $12 \times$ 10 last trials of C2(GPi On/saline)] with post hoc pairwise comparisons using Dunn's test for multiple comparisons of independent samples; $p$ values have been adjusted according to the false discovery rate (FDR) procedure of Benjamini-Hochberg. Results were obtained from raw data using the PMCMR R package (Pohlert, 2014). Significance level was set at $p<0.01$. Experimental raw data is available from (Kase \& Boraud, 2017) under a CCO license, theoretical raw data and code are available from (Rougier \& Topalidou, 2017) under a CCO license (data) and BSD license (code). The data and the codes are also available as extended data (respectively model codes and experimental data files).

Table 5 Theoretical results statistical analysis on correct answers

\begin{tabular}{lll}
\hline H0 & statistic $\mathbf{~ H )}$ & p value \\
C0 start $=$ C2 start & 2.965 & 0.0051 \\
C1 start $=$ C2 start & 4.986 & $1.8 \mathrm{e}-6$ \\
C1 end $=$ C2 start & 3.099 & 0.0036
\end{tabular}

Kruskal-Wallis rank sum test between the three conditions [saline (C0), muscimol (C1), or saline following muscimol (C2)] with post hoc pairwise comparisons using Dunn's test for multiple comparisons of independent samples. The script used for the analysis ( $R$ language) is available from Rougier and Topalidou (2017). 


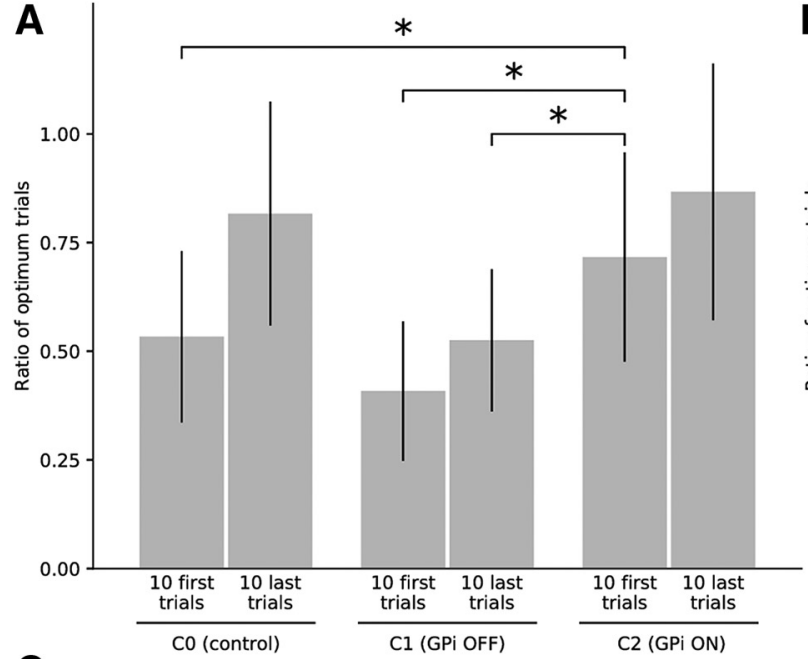

C
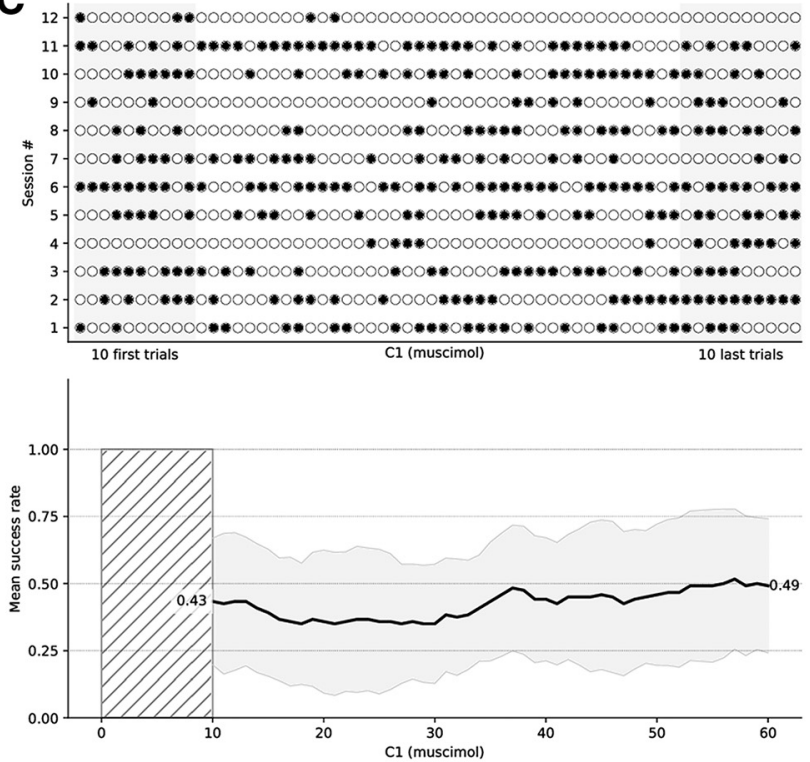

D
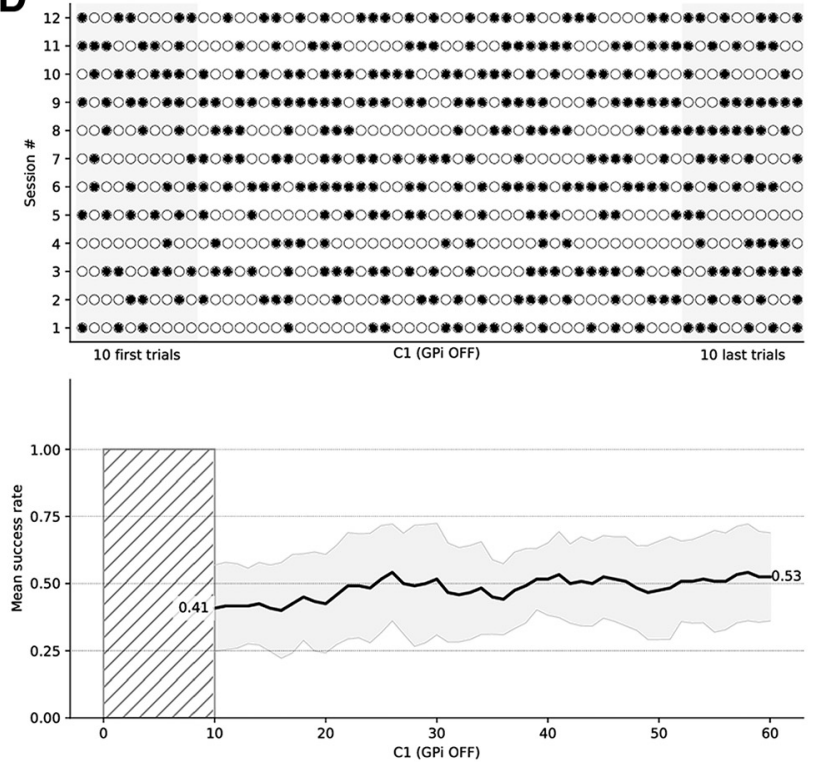

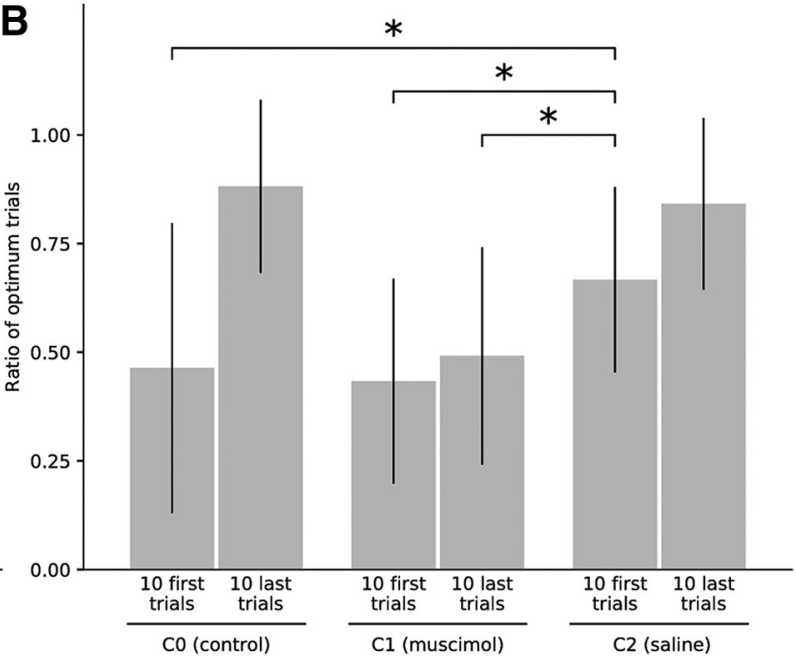

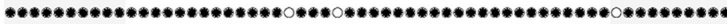

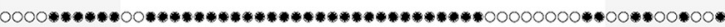

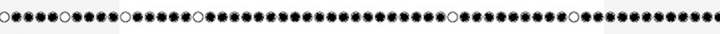

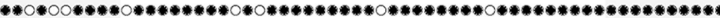

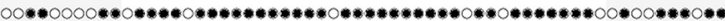

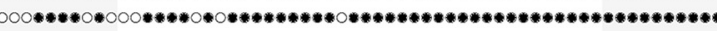

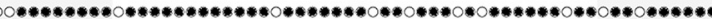
O 0 O

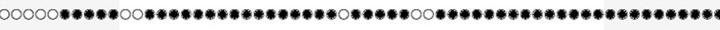

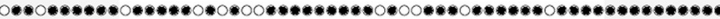

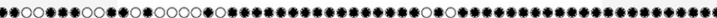

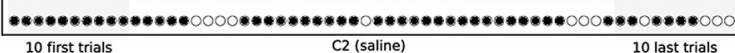

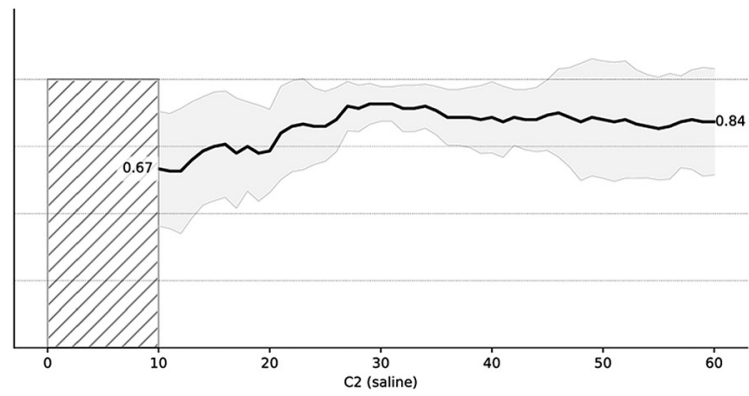

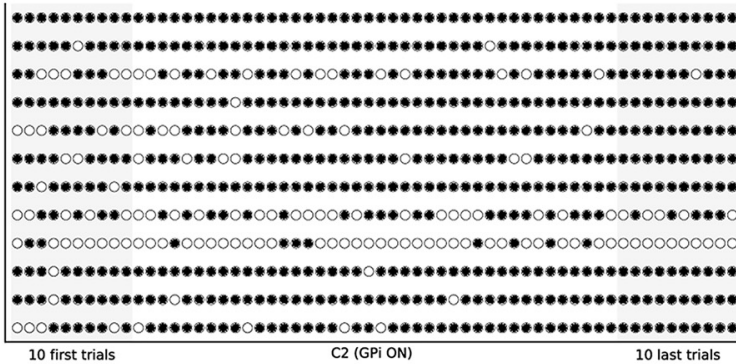

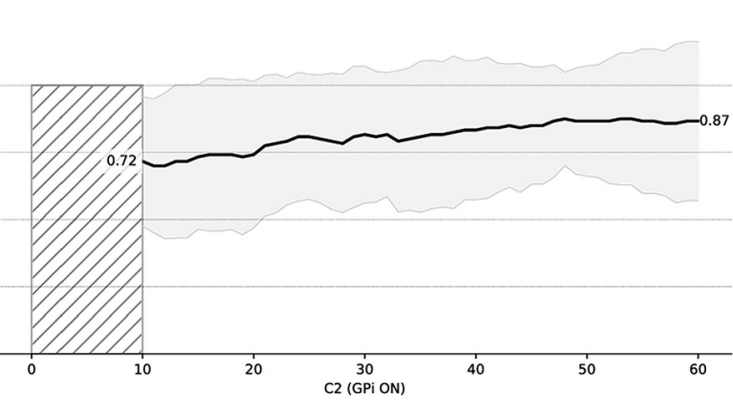

Figure 7. Theoretical and experimental results. Histograms show the mean performance at the start and the end of a session in $\mathrm{C} 1$ 
continued

and $\mathrm{C} 2$ conditions for both the model $(\boldsymbol{A})$ and the monkeys $(\boldsymbol{B})$. At the start of $\mathrm{C} 2$, the performance for both the model and the monkeys is significantly higher compared to the start and end of $\mathrm{C} 1$, suggesting that covert learning has occurred during $\mathrm{C} 1$ although performances are random during C1. C, Individual trials $(n=2 \times 60)$ for all the sessions $(n=12)$ for the primates (monkey 1 : sessions 1-7, monkey 2: sessions $8-12)$. $\boldsymbol{D}$, Individual trials $(n=2 \times 60)$ for all the sessions $(n=12)$ for the model. A black dot means a successful trial (the best stimulus has been chosen), an outlined white dot means a failed trial (the best stimulus has not been chosen). Measure of success is independent of the actual reward received after having chosen one of the two stimuli. The bottom part of each panel shows the mean success rate over a sliding window of ten consecutive trials and averaged across all the sessions. The thick black line is the actual mean and the gray-shaded area represents the SD over sessions.

\section{Results}

Our model predicts that the evaluation of options and the behavioral outcome are two separate (but entangled) processes. This means that if we block the output of the BG before learning, reinforcement learning still occurs at the striatal level under dopaminergic control and should induce covert learning of stimuli value although the behavioral choice would appear as random.

\section{Protocol}

The protocol has been consequently split over two consecutive conditions (C1 and $\mathrm{C} 2)$ using the same set of stimuli and a dissociated control (CO) using a different set of stimuli (using same probabilities as for $\mathrm{C} 1$ and $\mathrm{C} 2$ ):

C0 60 trials, GPi On (model), saline injection (primates), stimulus set $1\left(A_{1}, B_{1}\right)$ with $P A_{1}=0.75, P B_{1}=0.25$

C1 60 trials, GPi Off (model), muscimol injection (primates), stimulus set $2\left(A_{2}, B_{2}\right)$ with $P A_{2}=0.75, P B_{2}=$ 0.25

C2 60 trials, GPi On (model), saline injection (primates), stimulus set $2\left(A_{2}, B_{2}\right)$ with $P A_{2}=0.75, P B_{2}=0.25$

\section{Computational results}

We tested our hypothesis on the model using 12 different sessions (corresponding to 12 different initializations of the model). On day 1 (condition $\mathrm{C} 1$ ), we suppressed the GPi output by cutting the connections between the GPi and the thalamus. When the GPi output has been suppressed, the performance is random at the beginning, as shown by the average probability of choosing the best option (expressed as mean \pm SD) in the first 10 trials $(0.408 \pm 0.161)$, and remains so until the end of the session $(0.525 \pm 0.164)$. Statistical analysis revealed that no significant difference between the 10 first and 10 last trials. On day 2 (condition C2), we reestablished the connections between GPi and thalamus and tested the model to the same task as in $\mathrm{C} 1$ using the same set of stimuli. Results show a significant change in behavior: the model starts with an above-chance performance on the first 10 trials $(0.717 \pm 0.241)$, and this change is significant (Table 5; Fig. 7) compared to the start of $\mathrm{C} 1$, compared to the end of $\mathrm{C} 1$ and compared to the start of $\mathrm{CO}$, confirming our hypothesis that the BG have previously learned the value of stimuli although they were unable to alter the behavior of the model.

\section{Experimental results}

We tested the prediction of the model on two female macaque monkeys which have been implanted with two cannula guides into their left and right GPi (for details, see
Materials and Methods). To inhibit the GPi, we injected bilaterally a GABA agonist (muscimol, $1 \mu \mathrm{g}$ ) $15 \mathrm{~min}$ before working session on day 1 (condition $\mathrm{C} 1$ ). The two monkeys were trained for seven and five sessions, respectively, using the same set of stimuli for each session. Results show that animals were unable to choose the best stimulus in such condition from the start $(0.433 \pm 0.236)$ to the end $(0.492 \pm 0.250)$ of the session. Statistical analysis revealed no significant difference between the 10 first and 10 last trials in C1. On day 2 (condition C2), we injected bilaterally a saline solution 15 min before working session, and animals had to perform the same protocol as in C1. Results show a significant change in behavior (Table 6; Fig. 7): animals start with an above-chance performance on the first 10 trials $(p=0.667 \pm 0.213)$, compared to the start of $\mathrm{C} 1$, compared to the end of $\mathrm{C} 1$ and compared to the start of $\mathrm{CO}$, confirming our hypothesis that the BG has previously learned the value of stimuli.

\section{Discussion}

\section{Revisiting an old idea}

The model architecture we proposed in this manuscript is not totally original in the sense that the model implements known pathways that have been established for quite a long time and taken into account in a number of models. More precisely, several computational models in the literature include both the inner BG pathways as well as the feed-forward and feed-back loops from and to the cortex (through thalamus). However, most of these models (if not all) put a specific emphasis on the role of the BG without considering the cortex as a decision-making structure. To the best of our knowledge, virtually none of these models take advantage of a dual competition mechanism similar to the one we introduced. For example, the model by O'Reilly and Frank (2006), which solves the temporal and structural credit assignment problems on a working memory task, includes a Hebbian learning component for the posterior cortical part; however, O'Reilly

\section{Table 6 Experimental results}

\begin{tabular}{lll}
\hline H0 & statistic $(\mathbf{H})$ & p value \\
C0 start $=$ C2 start & 3.181 & 0.0024 \\
C1 start $=$ C2 start & 3.738 & 0.0004 \\
C1 end $=$ C2 start & 2.803 & 0.0069
\end{tabular}

Statistical analysis on correct answers. Kruskal-Wallis rank sum test between the three conditions [saline (C0), muscimol (C1), or saline following muscimol (C2)] with post hoc pairwise comparisons using Dunn's test for multiple comparisons of independent samples. The script used for the analysis ( $R$ language) is available from Rougier and Topalidou (2017). 

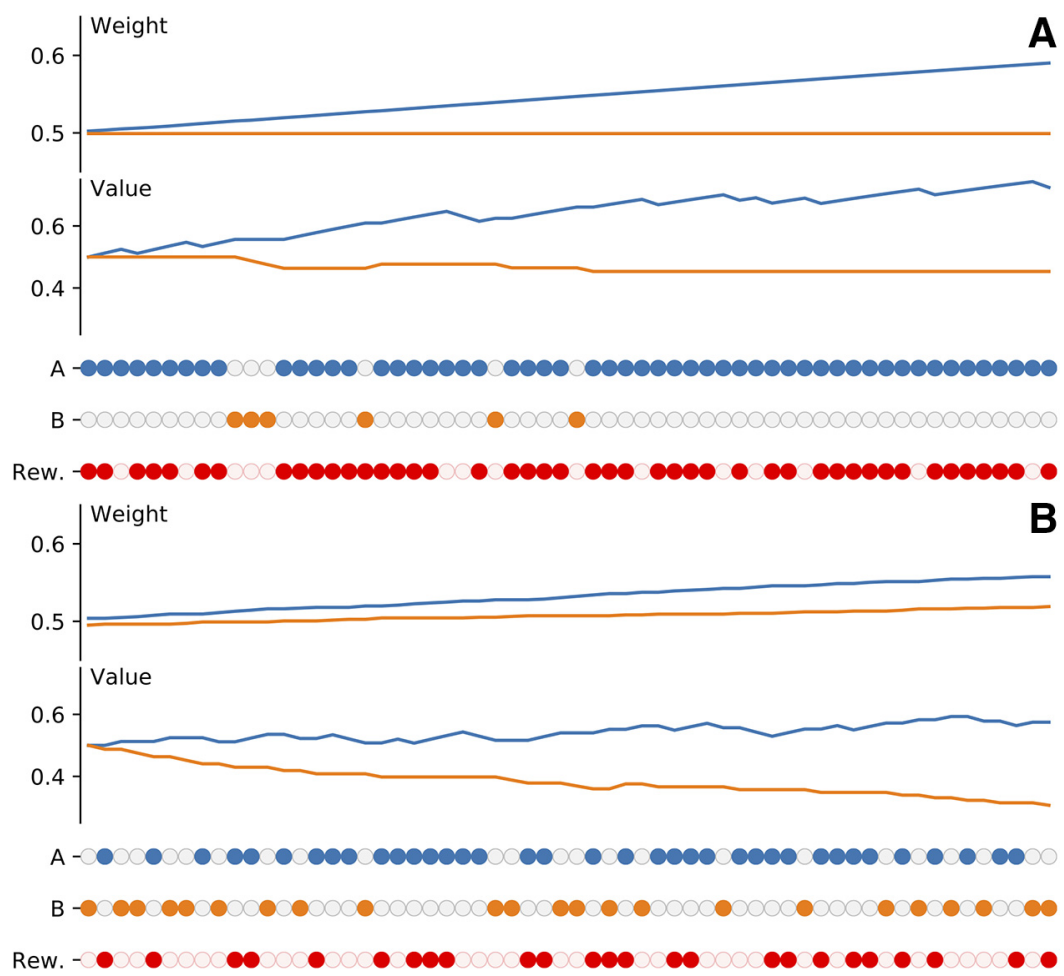

Figure 8. Model performance during a single session. Filled dots indicate the chosen cue between $A$ and $B$. Filled red dots indicate if a reward has been received following the choice. Reward probability is 0.75 for cue $A$ and 0.25 for cue $B$, but the displayed values are computed according to the actual reward received for each option. They are based on the history of the session, not the theoretical values. $\boldsymbol{A}$, Intact model (C0). The BG output drives the decision and evaluates the value of cue A and cue B with a strong bias in favor of $A$, because this cue is chosen more frequently. In the meantime, the Hebbian weight relative to this cue is strongly increased, while the weight relative to the other cue does not change significantly. $B$, Lesioned model (C1). The BG output has been suppressed and decisions are random. Hebbian weights for cue $A$ and cue $B$ are both increased up to similar values at the end of the session. In the meantime, the value of cue $A$ and cue $B$ are evaluated within the $B G$ and the random sampling of cue $A$ and cue $B$ leads to an actual better sampling of value $A$ and $B$. This is clearly indicated by the estimated value of $B$ that is very close to the theoretical value $(0.25)$

and Frank (2006) show that Hebbian learning is not critical for performances (only a $5 \%$ drop in performance) and did not specifically study lesions in the BG. Similarly, the model by Brown et al. (2004) does include a laminar frontal part with a specific emphasis on the interaction between the $B G$ and the frontal cortex and explain how to balance between reactive and planned behaviors. However, authors considers that "lesions of the BG uniquely cause devastating disorders of the voluntary movement system," which is not always the case as we have shown with experimental data (Desmurget and Turner, 2010; Piron et al., 2016). The model by Schroll et al. (2014) and Villagrasa et al. (2018) is notably similar to our own model and suggests that the CBG pathway is not required to perform previously well-learned SR associations, which is quite consistent with our own hypothesis. By using a simple S-R association tasks, authors show that a focal GPi lesion do not impact significantly performances over a previously well learned task. This is made possible thanks to the cortico-thalamic pathway that learn "to interconnect those cortical and thalamic neurons that are simultaneously activated via reward-sensitive BG pathways." The main difference with our own model is the localization of the Hebbian learning and the lateral competition. We hypothesize this learning to occur at the cortical level and take advantage of a lateral competition mechanism that is necessary to solve our decision task (while it is not necessary for a simple S-R task). This lateral competition acts indeed as a Go/NoGo substitute in the absence of the BG output. Furthermore, authors did not specifically conclude on the presence of covert learning when GPi is lesioned. They showed that the model has very bad performance when learning a new task, but they did not test the model once GPi is unlesioned. We suspect that if they had tested it, they would have found results similar to our own.

\section{Covert learning in the BG}

These results reinforce the classical idea that the BG architecture is based on an actor critic architecture where the dopamine serves as a reinforcement signal. However, the proposed model goes beyond this classical hypothesis and proposes a more general view on the role of the $B G$ in behavior and their entanglement with the cortex. Our results, both theoretical and experimental, suggest that the critic part of the $B G$ extends its role beyond the $B G$ and makes it de facto a central component in behavior that evaluates any action, independently of their origin. This hypothesis is very congruent with the results introduced in Charlesworth et al. (2012), where authors show 


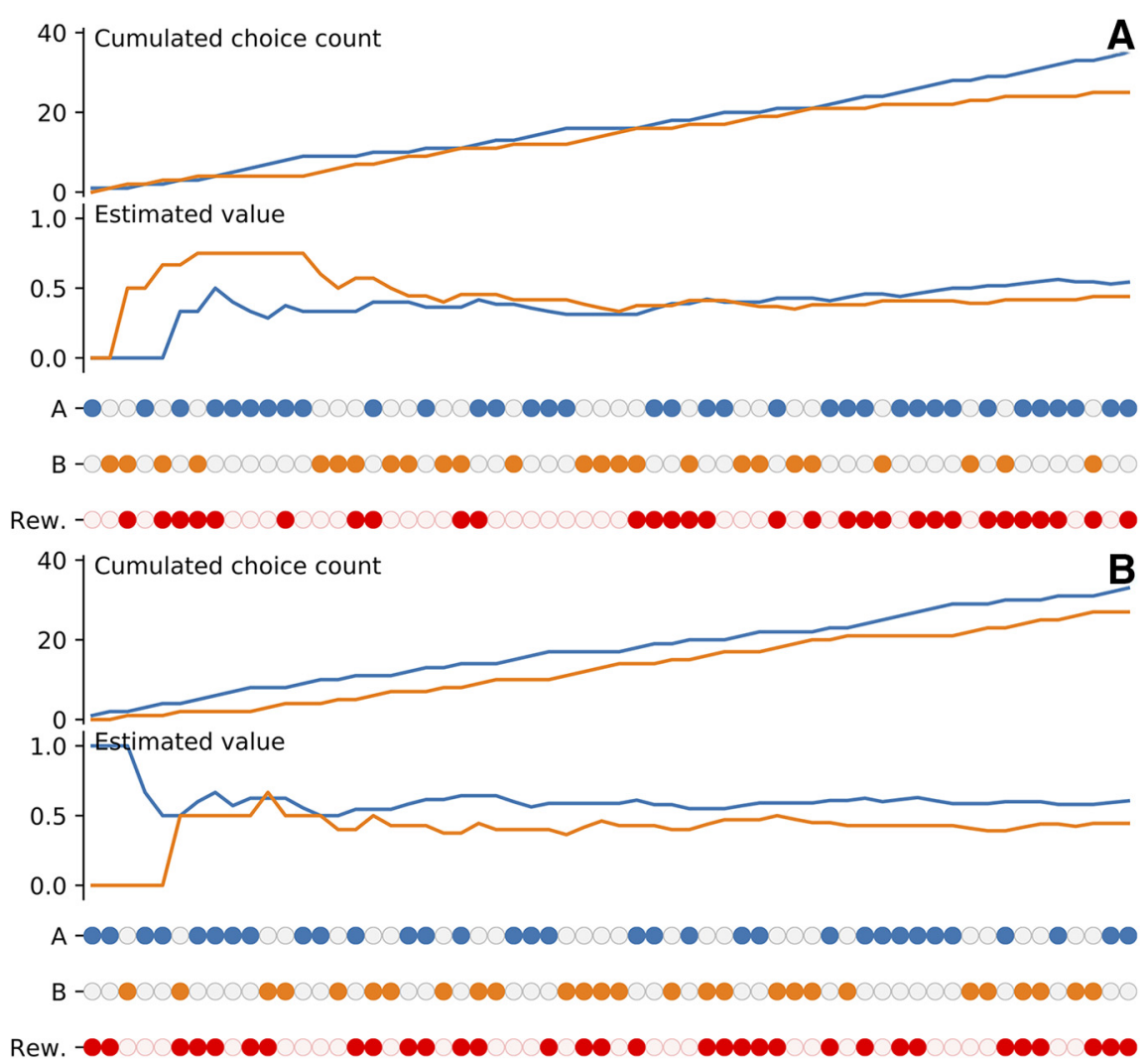

Figure 9. Monkey performance during a single session. Filled dots indicate the chosen cue between A and B. Filled red dots indicate if a reward has been received following the choice. Reward probability is 0.75 for cue $A$ and 0.25 for cue B, but the displayed values are computed according to the actual reward received for each option. They are based on the history of the session, not the theoretical values. $\boldsymbol{A}$, In saline condition (C), the monkey is able to slowly choose for the best cue with a slight preferences for A at the end of the 60 trials. Estimation of the perceived value of the two cues shows the actual value of $A$ is greater than the value of $B$ at the end of the session $\boldsymbol{B}$, In muscimol condition (C1), the monkey chooses cues randomly as indicated by the overall count of choices $A$ and $B$. Estimation of the perceived value of the two cues (dashed lines) reveals a greater estimation of the value of $A$ compared to the value of $B$.

that the anterior forebrain pathway in Bengalese finches contributes to skill learning even when it is blocked and does not participate in the behavioral performance. This is also quite compatible with the hypothesis that the $B G$ is a general purpose trainer for corticocortical connections as proposed by Ashby et al. (2010) and Hélie et al. (2015). Here, we introduced a precise computational model using both reinforcement and Hebbian learning, supported by experimental data, that explains precisely how this general purpose trainer can be biologically implemented.

This can be simply understood by scrutinizing a session in control and lesion condition (Fig. 8). In control condition, the model learns to select the best cue thanks to the BG. Learning the best stimulus induces a preferential selection of the best stimulus to obtain a higher probability of reward. If the process is repeated over many trials, this leads implicitly to an over- representation of the more valuable stimuli at the cortical level and consequently, Hebbian learning will naturally reinforce this stimulus. In the lesion condition, selection is random and each stimulus is roughly selected with equal probability, which allows the BG to evaluate the two stimuli even more precisely. We believe this is the same for the monkeys although we do not have access to internal values and weights. However, we can see in Figure 9 that the estimated value of stimuli (computed as the probability of reward) reflects the highest value for the best stimulus. Similarly, the number of times a given stimulus has been selected is correlated with its actual value.

\section{From reinforcement to Hebbian learning}

These new results, together with our previous results (Piron et al., 2016), shed light on a plausible neural mechanism responsible for the gradual mix between an A-O and a S-R behavior. The novelty in our hypothesis is that two systems that act and learn together, and we tend to disagree with the hypothesis of a hierarchical system (Dezfouli and Balleine, 2013). In our case, the final behavioral decision results from a subtle balance between the two decisions. When a new task needs to be solved, the $B G$ initially drives the decision because initially it has a faster dynamic. In the meantime, the cortex takes advantage of this driving, and gradually learns the decision independently of the reward. We've shown how this could be the case for monkeys, although we lack experimental evidence that the decision in muscimol condition is actually driven by the cortex. The actual combination of the 
two systems might be more complex than a simple weighted linear combination and this make the study even more difficult to carry on. What we see at the experimental level might be the projection of a more complex phenomenon. Persisting in a devaluated task does not mean that the system is frozen, but the time to come back from a S-R oriented behavior might be simply longer than the time to initially acquire the behavior.

\section{References}

Alexander GE, Crutcher MD (1990) Functional architecture of basal ganglia circuits: neural substrates of parallel processing. Trends Neurosci 13:266-271. Medline

Alexander GE, DeLong MR, Strick PL (1986) Parallel organization of functionally segregated circuits linking basal ganglia and cortex. Annu Rev Neurosci 9:357-381. CrossRef Medline

Alexander GE, Crutcher MD, DeLong MR (1991) Basal gangliathalamocortical circuits: parallel substrates for motor, oculomotor, "prefrontal" and "limbic" functions. Prog Brain Res 85:119-146. Medline

Amari SI (1977) Dynamics of pattern formation in lateral-inhibition type neural fields. Biol Cybern 27:77-87. CrossRef

Ashby FG, Turner BO, Horvitz JC (2010) Cortical and basal ganglia contributions to habit learning and automaticity. Trends Cogn Sci 14:208-215. CrossRef

Auer P, Cesa-Bianchi N, Freund Y, Schapire RE (2002) The nonstochastic multiarmed bandit problem. SIAM J Comput 32:48-77. CrossRef

Bar-Gad I, Bergman H (2001) Stepping out of the box: information processing in the neural networks of the basal ganglia. Curr Opin Neurobiol 11:689-695. CrossRef Medline

Bear MF, Malenka RC (1994) Synaptic plasticity: LTP and LTD. Curr Opin Neurobiol 4:389-399. CrossRef Medline

Bradshaw CM, Szabadi E, Bevan P, Ruddle HV (1979) The effect of signaled reinforcement availability on concurrent performances in humans. J Exp Anal Behav 32:65-74. CrossRef Medline

Brown JW, Bullock D, Grossberg S (2004) How laminar frontal cortex and basal ganglia circuits interact to control planned and reactive saccades. Neural Netw 17:471-510. CrossRef Medline

Brown LL, Smith DM, Goldbloom LM (1998) Organizing principles of cortical integration in the rat neostriatum: corticostriate map of the body surface is an ordered lattice of curved laminae and radial points. J Comp Neurol 392:468-488. CrossRef Medline

Callaway EM (1998) Local circuits in primary visual cortex of the macaque monkey. Annu Rev Neurosci 21:47-74. CrossRef Medline

Caporale N, Dan Y (2008) Spike timing-dependent plasticity: a Hebbian learning rule. Annu Rev Neurosci 31:25-46. CrossRef Medline

Charlesworth JD, Warren TL, Brainard MS (2012) Covert skill learning in a cortical-basal ganglia circuit. Nature 486:251-255. CrossRef Medline

Coultrip R, Granger R, Lynch G (1992) A cortical model of winnertake-all competition via lateral inhibition. Neural Netw 5:47-54. CrossRef

Cowan RL, Wilson CJ (1994) Spontaneous firing patterns and axonal projections of single corticostriatal neurons in the rat medial agranular cortex. J Neurophysiol 71:17-32. CrossRef Medline

Deco G, Ponce-Alvarez A, Hagmann P, Romani GL, Mantini D, Corbetta M (2014) How local excitation- inhibition ratio impacts the whole brain dynamics. J Neurosci 34:7886-7898. CrossRef Medline

Desmurget M, Turner RS (2010) Motor sequences and the basal ganglia: kinematics, not habits. J Neurosci 30:7685-7690. CrossRef

Dezfouli A, Balleine BW (2013) Actions, action sequences and habits: evidence that goal-directed and habitual action control are hierarchically organized. PLoS Comput Biol 9:e1003364. CrossRef Medline
Doll BB, Simon DA, Daw ND (2012) The ubiquity of model-based reinforcement learning. Curr Opin Neurobiol 22:1075-1081. CrossRef Medline

Dougan JD, McSweeney FK, Farmer VA (1985) Some parameters of behavioral contrast and allocation of interim behavior in rats. J Exp Anal Behav 44:325-335. CrossRef Medline

Doya K (2000) Complementary roles of basal ganglia and cerebellum in learning and motor control. Curr Opin Neurobiol 10:732-739. CrossRef Medline

Doya K (2007) Reinforcement learning: computational theory and biological mechanisms. HFSP J 1:30-40. CrossRef Medline

Feldman DE (2009) Synaptic mechanisms for plasticity in neocortex. Annu Rev Neurosci 32:33-55. CrossRef Medline

Flaherty AW, Graybiel AM (1991) Corticostriatal transformations in the primate somatosensory system. projections from physiologically mapped body-part representations. J Neurophysiol 66:12491263. CrossRef Medline

Frank MJ (2004) By carrot or by stick: cognitive reinforcement learning in parkinsonism. Science 306:1940-1943. CrossRef Medline

Gilbert-Norton LB, Shahan TA, Shivik JA (2009) Coyotes (Canis latrans) and the matching law. Behav Processes 82:178-183. CrossRef

Gittins JC (1979) Bandit processes and dynamic allocation indices. $J$ R Stat Soc Series B Stat Methodol 41:148-177. CrossRef

Glimcher PW (2011) Understanding dopamine and reinforcement learning: the dopamine reward prediction error hypothesis. Proc Natl Acad Sci USA 108:15647-15654. CrossRef Medline

Graft DA, Lea SEG, Whitworth TL (1977) The matching law in and within groups of rats1. J Exp Anal Behav 27:183-194. CrossRef Medline

Graybiel AM (2008) Habits, rituals, and the evaluative brain. Annu Rev Neurosci 31:359-387. CrossRef Medline

Graybiel AM, Aosaki T, Flaherty AW, Kimura M (1994) The basal ganglia and adaptive motor control. Science 265:1826-1831. CrossRef Medline

Gurney K, Prescott TJ, Redgrave P (2001) A computational model of action selection in the basal ganglia. II. analysis and simulation of behaviour. Biol Cybern 84:411-423. CrossRef Medline

Guthrie M, Leblois A, Garenne A, Boraud T (2013) Interaction between cognitive and motor cortico-basal ganglia loops during decision making: a computational study. J Neurophysiol 109: 3025-3040. CrossRef Medline

Haber SN (2003) The primate basal ganglia: parallel and integrative networks. J Chem Neuroanat 26:317-330. CrossRef Medline

Hélie S, Ell SW, Ashby FG (2015) Learning robust cortico-cortical associations with the basal ganglia: an integrative review. Cortex 64:123-135. CrossRef Medline

Herrnstein RJ (1974) Formal properties of the matching law1. J Exp Anal Behav 21:159-164. CrossRef Medline

Herrnstein RJ, Vaughan W, Mumford DB, Kosslyn SM (1989) Teaching pigeons an abstract relational rule: insideness. Percept Psychophys 46:56-64. CrossRef Medline

Hiratani N, Fukai T (2016) Hebbian wiring plasticity generates efficient network structures for robust inference with synaptic weight plasticity. Front Neural Circuits 10:41. CrossRef Medline

Hopfield JJ (1984) Neurons with graded response have collective computational properties like those of two-state neurons. Proc Natl Acad Sci USA 81:3088-3092. CrossRef Medline

Kase D, Boraud T (2017) Covert learning in the basal ganglia: raw data. Available at: https://figshare.com/articles/Covert_learning_in_the_basal_ganglia_raw_data/4753507.

Katehakis MN, Veinott AF (1987) The multi-armed bandit problem: decomposition and computation. Math Oper Res 12:262-268. CrossRef

Keasar T (2002) Bees in two-armed bandit situations: foraging choices and possible decision mechanisms. Behav Ecol 13:757765. CrossRef

Kerr JND, Wickens JR (2001) Dopamine d-1/d-5 receptor activation is required for long-term potentiation in the rat neostriatum in vitro. J Neurophysiol 85:117-124. CrossRef Medline 
Kincaid AE, Zheng T, Wilson CJ (1998) Connectivity and convergence of single corticostriatal axons. J Neurosci 18:4722-4731. CrossRef Medline

Lau B, Glimcher PW (2005) Dynamic response-by-response models of matching behavior in rhesus monkeys. J Exp Anal Behav 84: 555-579. CrossRef Medline

Lau B, Glimcher PW (2008) Value representations in the primate striatum during matching behavior. Neuron 58:451-463. CrossRef Medline

Leblois A, Boraud T, Meissner W, Bergman H, Hansel D (2006) Competition between feedback loops underlies normal and pathological dynamics in the basal ganglia. J Neurosci 26:3567-3583. CrossRef Medline

Matthews LR, Temple W (1979) Concurrent schedule assessment of food preference in cows. J Exp Anal Behav 32:245-254. CrossRef Medline

Mink JW (1996) The basal ganglia: focused selection and inhibition of competing motor programs. Prog Neurobiol 50:381-425. CrossRef Medline

Mishkin M, Malamut B, Bachevalier J (1984) Memories and habits: two neural systems. In: Neurobiology of human learning and memory (Lynch G, McGaugh JL, Weinberger NM, eds). New York, NY: Guilford.

Muir DR, Cook M (2014) Anatomical constraints on lateral competition in columnar cortical architectures. Neural Comput 26:16241666. CrossRef Medline

Naruse M, Berthel M, Drezet A, Huant S, Aono M, Hori H, Kim S-J (2015) Single-photon decision maker. Sci Rep 5:13253. CrossRef Medline

Nisenbaum ES, Wilson CJ (1995) Potassium currents responsible for inward and outward rectification in rat neostriatal spiny projection neurons. J Neurosci 15:4449-4463. CrossRef Medline

Niv Y, Langdon A (2016) Reinforcement learning with Marr. Curr Opin Behav Sci 11:67-73. CrossRef Medline

O'Reilly RC, Frank MJ (2006) Making working memory work: a computational model of learning in the prefrontal cortex and basal ganglia. Neural Comput 18:283-328. CrossRef Medline

Oorschot DE (1996) Total number of neurons in the neostriatal, pallidal, subthalamic, and substantia nigral nuclei of the rat basal ganglia: a stereological study using the cavalieri and optical disector methods. J Comp Neurol 366:580-599. CrossRef Medline

Packard MG, Knowlton BJ (2002) Learning and memory functions of the basal ganglia. Annu Rev Neurosci 25:563-593. CrossRef Medline

Parent A, Sato F, Wu Y, Gauthier J, Lévesque M, Parent M (2000) Organization of the basal ganglia: the importance of axonal collateralization. Trends Neurosci 23:S20-S27. Medline

Parthasarathy H, Schall J, Graybiel AM (1992) Distributed but convergent ordering of corticostriatal projections: analysis of the frontal eye field and the supplementary eye field in the macaque monkey. J Neurosci 12:4468-4488. Medline

Pasquereau B, Nadjar A, Arkadir D, Bezard E, Goillandeau M, Bioulac B, Gross CE, Boraud T (2007) Shaping of motor responses by incentive values through the basal ganglia. J Neurosci 27:11761183. CrossRef Medline

Pawlak V, Kerr JND (2008) Dopamine receptor activation is required for corticostriatal spike-timing-dependent plasticity. J Neurosci 28:2435-2446. CrossRef Medline

Piron C, Kase D, Topalidou M, Goillandeau M, Orignac H, N'Guyen TH, Rougier NP, Boraud T (2016) The globus pallidus pars interna in goal-oriented and routine behaviors: resolving a long-standing paradox. Mov Disord 31:1146-1154. CrossRef Medline

Plowright C, Shettleworth SJ (1990) The role of shifting in choice behavior of pigeons on a two-armed bandit. Behav Processes 21:157-178. CrossRef

Pohlert T (2014). The pairwise multiple comparison of mean ranks package (pmcmr). R Package. Available at http://CRAN.R-project.org/package $=$ PMCMR.
Redgrave P, Gurney K, Reynolds J (2008) What is reinforced by phasic dopamine signals? Brain Res Rev 58:322-339. CrossRef Medline

Reid CR, MacDonald H, Mann RP, Marshall JAR, Latty T, Garnier S (2016) Decision-making without a brain: how an amoeboid organism solves the two-armed bandit. J R Soc Interface 13:20160030. CrossRef

Reynolds JNJ, Hyland BI, Wickens JR (2001) A cellular mechanism of reward-related learning. Nature 413:67-70. CrossRef Medline

Robbins H (1952) Some aspects of the sequential design of experiments. Bull Am Math Soc 58:527-536. CrossRef

Rougier NP, Topalidou M (2017). Covert learning in the basal ganglia: code. Available at https://github.com/rougier/one-critic-twoactors.

Sandstrom MI, Rebec GV (2003) Characterization of striatal activity in conscious rats: contribution of NMDA and AMPA/kainate receptors to both spontaneous and glutamate-driven firing. Synapse 47:91-100. CrossRef Medline

Schroll H, Vitay J, Hamker FH (2014) Dysfunctional and compensatory synaptic plasticity in Parkinson's disease. Eur J Neurosci 39:688-702. CrossRef Medline

Seger CA, Spiering BJ (2011) A critical review of habit learning and the basal ganglia. Front Syst Neurosci 5:66. CrossRef Medline

Shriki O, Hansel D, Sompolinsky H (2003) Rate models for conductance-based cortical neuronal networks. Neural Comput 15:1809-1841. CrossRef Medline

Steyvers M, Lee MD, Wagenmakers E-J (2009) A bayesian analysis of human decision-making on bandit problems. J Math Psychol 53:168-179. CrossRef

Suri RE (2002) TD models of reward predictive responses in dopamine neurons. Neural Netw 15:523-533. Medline

Suri RE, Schultz W (1999) A neural network model with dopaminelike reinforcement signal that learns a spatial delayed response task. Neuroscience 91:871-890. CrossRef Medline

Surmeier DJ, Ding J, Day M, Wang Z, Shen W (2007) D1 and d2 dopamine-receptor modulation of striatal glutamatergic signaling in striatal medium spiny neurons. Trends Neurosci 30:228-235. CrossRef Medline

Sutton RS, Barto AG (1998) Reinforcement learning: an introduction. Massachusetts: MIT Press.

Takada M, Tokuno H, Hamada I, Inase M, Ito Y, Imanishi M, Hasegawa N, Akazawa T, Hatanaka N, Nambu A (2001) Organization of inputs from cingulate motor areas to basal ganglia in macaque monkey. Eur J Neurosci 14:1633-1650. CrossRef Medline

Taylor JG (1999) Neural 'bubble' dynamics in two dimensions: foundations. Biol Cybern 80:393-409. CrossRef

Villagrasa F, Baladron J, Vitay J, Schroll H, Antzoulatos EG, Miller EK, Hamker FH (2018) On the role of cortex-basal ganglia interactions for category learning: a neurocomputational approach. J Neurosci 38:9551-9562. CrossRef Medline

von der Malsburg C (1973) Self-organization of orientation sensitive cells in the striate cortex. Kybernetik 14:85-100. CrossRef

Webster K (1961) Cortico-striate interrelations in the albino rat. $J$ Anat 95:532-544. Medline

Wilson CJ (1987) Morphology and synaptic connections of crossed corticostriatal neurons in the rat. J Comp Neur 263:567-580. CrossRef Medline

Wilson CJ, Groves PM (1981) Spontaneous firing patterns of identified spiny neurons in the rat neostriatum. Brain Res 220:67-80. CrossRef Medline

Wilson HR, Cowan JD (1972) Excitatory and inhibitory interactions in localized populations of model neurons. Biophys $J$ 12:1-24. CrossRef Medline

Wilson HR, Cowan JD (1973) A mathematical theory of the functional dynamics of cortical and thalamic nervous tissue. Kybernetik 13: 55-80. CrossRef Medline

Yin HH, Knowlton BJ (2006) The role of the basal ganglia in habit formation. Nat Rev Neurosci 7:464-476. CrossRef Medline 